\title{
Productivity Growth of Transition Economies: An Assessment
}

\author{
Massimo Giannini, Luca Vitali* \\ University of Rome Tor Vergata Via Bernardino Alimena, 5 - 00173 Roma \\ *Corresponding Author: luca.vitali@uniroma2.it
}

Copyright (C) 2014 Horizon Research Publishing All rights reserved.

\begin{abstract}
Accession to the euro area is a long term process that is still under way for most transition economies, and different paths to macroeconomic stabilization were adopted by local authorities. This study is based on data for three groups of countries: EEC Eastern European countries (Bulgaria, Croatia, Czech Republic, Hungary, Poland, Slovak Republic, Slovenia, Ukraine), BC Baltic countries (Estonia, Latvia, Lithuania), CEC Core European countries (France, Germany, Italy). We acknowledge that, well beyond plain "economic convergence", the integration process is affected by peculiar political pressures; nonetheless our aim is to determine whether a group of countries is better suited to enter the euro area (more "EMU-ready"), or if transition economies does not share a common growth pattern with core European countries. Although labour productivity points to a substantial convergence of transition economies, kernel estimation methods shows a twin peak (bimodal) distribution, providing evidence against the convergence hypothesis. We use non-parametric, linear programming technique DEA to compare efficiency of decision-making units (DMUs). Since evidence is quite puzzling, decomposition of Malmquist productivity index is needed. Lastly, a tentative explanation of productivity growth through governance indicators is proposed.
\end{abstract}

Keywords Convergence, Efficiency, Transition Economies and Data Envelopment Analysis

\section{Introduction}

After the collapse of the iron curtain, the transition process from centrally planned economies towards free markets led Eastern European countries to a progressive improvement of living standards. Baltic states (Estonia, Latvia, and Lithuania) enjoyed an impressive growth in GDP per capita, averaging 5 percent or more a year, while the pace of economic improvement has been a little slower in Czech Republic, Poland, Slovak Republic, Slovenia and in South eastern European countries such as Bulgaria and Croatia. On the whole, all countries have transitioned sufficiently to achieve
EU membership.

Since transition is a composite and complex process of transformation which includes liberalization, macroeconomic stabilization, privatization, and legal and institutional reforms, the path to a market economy is affected by the initial standings and the internal factors in each country, and heavily relies on the trade integration process, which proceeded rapidly among EU members since the completion of the internal market in the late 1980s and has then accelerated since the accession of the "new EU-12" countries (Slovakia, Slovenia, Czech Republic, Estonia, Lithuania, Latvia, Poland, Cyprus, Malta, Hungary, Romania and Bulgaria). However, the achievement of better economic conditions also brought along socio-economic costs. The impact of EU's common external tariff and product and labour market regulations have added to the regulatory burden of enterprises and made convergence harder for poorest nations.

To shed more light on the transition towards a broader European Union, a proper assessment of efficiency gains arising from such process is needed, together with a proper evaluation of the smoothness of those changing environments. For purposes to be discussed next, we select three groups of countries: EEC Eastern European countries (Bulgaria, Croatia, Czech Republic, Hungary, Poland, Slovak Republic, Slovenia, Ukraine), BC Baltic countries (Estonia, Latvia, Lithuania), CEC Core European countries (France, Germany, Italy).

In this paper we use descriptive and empirical analysis to examine the convergence hypothesis; our findings do not seem to corroborate such view. Our paper is similar in spirit and methodology to Fare, Grosskopf and Margaritis 2006. However, unlike these authors, we do not find clear evidence of convergence among European countries. Our results are better related to Quah findings (1996a, 1996b) about the "twin peak" property of the growth rate distribution and to Mora, Vaya and Surinach, 2005 who stress that a club convergence is under way in Europe. Evidence in favour of convergence and integration is also supported in Kutan and Yigit, 2007; they develop a theoretical stochastic growth model which as a foundation for empirical research. Economic integration is thus beneficial to member countries, 
especially from a long-run perspective, and that cohesion and structural funds help new members in the catching-up process to core-EU members standards of living. Further, Kutan and Yigit 2009, find that, taking into account labor productivity, the result of convergence and catching-up, although at work, seems less clear. A recent contribution by Novak, 2011 sheds light upon real convergence between the EU8 and EU15 economies using longitudinal data. A statistically significant negative relationship between average growth of labour productivity and the initial value of labour productivity level is observed. However, there is a clear lack of systematic convergence between EU8 and EU15 economies. This implies that individual economies from the EU23 group (i.e., EU8 + EU15) converge to their own steady state, but when these groups are accounted for as separate economies (EU8 and EU15) they show different patterns. As a result, integration of former socialist economies (also dubbed advanced transition economies) does not imply convergence of these economies towards the productivity levels of advanced market economies represented as EU15.

\section{Stylized Facts}

The sources of productivity growth of an economic system can be manifold but, simplifying the standard growth accounting framework and assuming that all production units operate efficiently, economic growth decomposes into contributions due to factor accumulation, as reflected in labour productivity and multifactor productivity (MFP). Labour productivity is defined as real output per unit of labour input, where labour input is measured in terms of the number of persons employed. On the other hand, MFP, which is defined as real output per unit of all (combined) inputs gives a more specific measure of productivity, for it captures the impact of several factors (such as improvements in organisation and quality of labour and capital) and is therefore identified with technological progress. Hence, the change in labour productivity could be ascribed either to an increase in the amount of capital available per person employed (i.e. capital deepening), or to an increase in the overall efficiency of the economic process (i.e. MFP) or both. Robert Solow (1956) first argued that, with a neoclassical production function, long-run growth in per capita income must be driven by growth in MFP; as a consequence, for countries aiming at a consistent catching-up process with most developed partners, productivity growth should reflect a persistent increase in MFP. Table 1 presents GDP and input factors' growth rates in the period 1996-2007 for our selection of countries. Transition economies show a substantial recovery from the integration shock experienced in the first half of the 90's in terms of GDP growth, while patterns regarding inputs where more volatile: labour force is pretty stable, with a slight increase after 2001, whereas capital stock variations are much more intense.

Demographic factors, associated with fast financial transition towards open markets, explain the extraordinarily high growth rates of output and labour productivity of Baltic countries. In the aftermath of 1989, Eastern European countries experienced aggregate demand improvements due to high inward flow of funds, coupled with an equally high outflow of labour through migration and a low number of young labour market entrants due to the collapse in fertility rates. Those trends were steeper for Baltic countries, which display twice the growth rates of fellow East European transitioners. Further, as quite evident from figure 1, which shows labour productivity of transition economies relative to core European countries, the productivity recovery from early 90's seems more intense for Baltic countries, in particular from 2001 onwards.

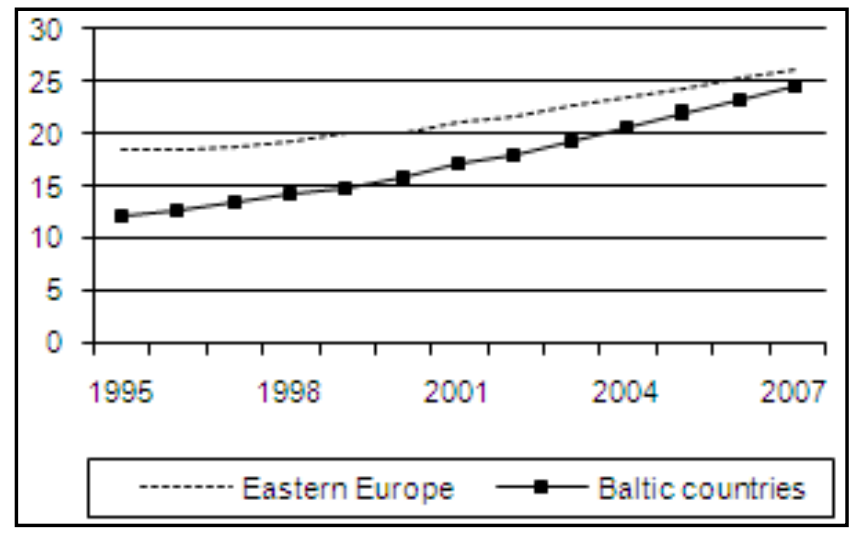

Figure 1. Relative levels of productivity versus core Europe (Eastern Europe and Baltic countries labour productivity as a percentage of the core Europe level, at constant prices)[6]

Table 1. Average growth rates [6]

\begin{tabular}{|c|c|c|c|c|c|c|c|c|c|c|c|c|}
\hline & \multicolumn{3}{|c|}{ Gross domestic product } & \multicolumn{3}{|c|}{ Labour force } & \multicolumn{3}{|c|}{ Capital stock } & \multicolumn{3}{|c|}{ Labour productivity } \\
\hline & $\begin{array}{l}1996- \\
2007\end{array}$ & $\begin{array}{l}1996- \\
2001 \\
\end{array}$ & $\begin{array}{l}2002- \\
2007\end{array}$ & $\begin{array}{l}1996- \\
2007 \\
\end{array}$ & $\begin{array}{l}1996- \\
2001 \\
\end{array}$ & $\begin{array}{c}2002- \\
2007 \\
\end{array}$ & $\begin{array}{l}1996- \\
2007\end{array}$ & $\begin{array}{l}1996- \\
2001 \\
\end{array}$ & $\begin{array}{l}2002- \\
2007\end{array}$ & $\begin{array}{l}1996- \\
2007 \\
\end{array}$ & $\begin{array}{l}1996- \\
2001 \\
\end{array}$ & $\begin{array}{r}2002- \\
2007 \\
\end{array}$ \\
\hline EEC & 3,80 & 2,60 & 5,16 & 0,33 & $-0,43$ & 1,08 & 9,66 & 11,32 & 7,99 & 2,79 & 2,94 & 2,74 \\
\hline $\mathrm{BC}$ & 7,21 & 5,85 & 8,59 & 0,48 & $-1,05$ & 2,01 & 10,38 & 9,61 & 11,14 & 5,24 & 5,80 & 4,97 \\
\hline CEC & 1,74 & 2,16 & 1,39 & 1,01 & 0,96 & 1,07 & 3,88 & 4,36 & 3,40 & 4,25 & 3,80 & 4,87 \\
\hline
\end{tabular}


As the "Innovation, Inclusion and Integration" report from the World Bank states, productivity gains and improvements in efficiency of transition economies largely occurred within industries, rather than from a reallocation of labour from less to more productive industries, at least in the manufacturing sector, so that firms acted in accordance with a "defensive restructuring" rather than a "strategic restructuring," (Grosfeld and Roland 1995). The limited contribution of employment shifts to the most efficient sectors of the economy supports the view that some low productivity industries may have been sheltered from competitive pressure. Our estimates confirm such view, showing that productivity gains could be mostly ascribed to technical progress rather than labour force movements towards more efficient activities.

Analysis of different growth patterns among groups of selected countries is also a worth mentioning issue. Did transition economies experienced a convergence process between themselves (probably reflected in different labour productivity growth rates) or, instead, different patterns of growth can bring those countries closer to the frontier at different times? Visual inspection of the trends of Eastern European countries towards the frontier, as defined by the leading technological nations (core Europe) doesn't show a great deal of convergence, as displayed in figure 2 , while the gap between the clusters transition economies progressively narrows.

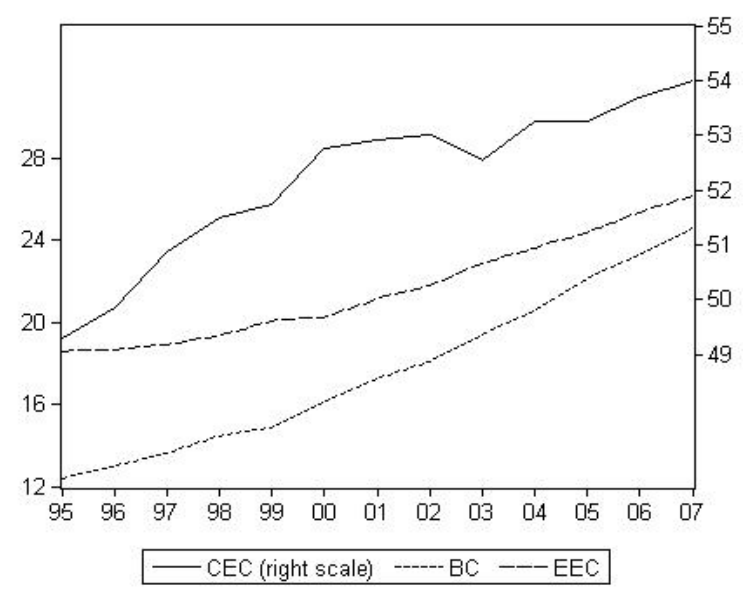

Figure 2. Labour productivity trends (1995-2007) [6]

However, labour productivity tells us only a part of the story, since the dynamics of production factors to more efficient uses requires decomposing MFP growth into efficiency change, represented by movements of the economy towards the frontier, and technological progress, represented by shifts of the production frontier. Over the long term, a very large contribution to growth comes from the efficiency in combining labour and capital inputs, hence further analysis is needed.

Accession to the euro area is a long term process that is still under way for most transition economies and acceding countries assumed different strategies regarding macroeconomic stabilization. The process of joining the EU started in 1998 with the Accession Group (Czech Republic, Estonia, Hungary, Poland and Slovenia). Another group of countries, the 2000 Accession Group, consisting of Bulgaria, Latvia, Lithuania, Romania and the Slovak Republic, followed in the negotiation process. Currently, Slovakia and Slovenia are part of the euro area; all other transition countries considered in our paper entered UE with the exception of Croatia, that is nonetheless involved in the negotiation process, while Ukraine political leaders have repeatedly shown their attention and involvement for UE. Given that the integration process has been different for different countries for reasons beyond plain "economic convergence", in our analysis we seek to identify whether a group of countries is "more EMU-ready" or better suited to enter the euro area, independently of formal agreements, which we refer to as "political" in a broad sense, or if the growth pattern of transition economies is peculiar and driven by common factors which are not shared with main European countries.

Such questions also arise from figure 3, where initial levels of real GDP per capita are displayed together with the average annual GDP growth. According to the absolute, $\beta$-convergence hypothesis, countries will grow much more rapidly if they initially lagged behind rich countries and such process leads to the equalization of these countries' GDP per capita. Further, a separation into different groups of countries with peculiar growth patterns seems rather clear.

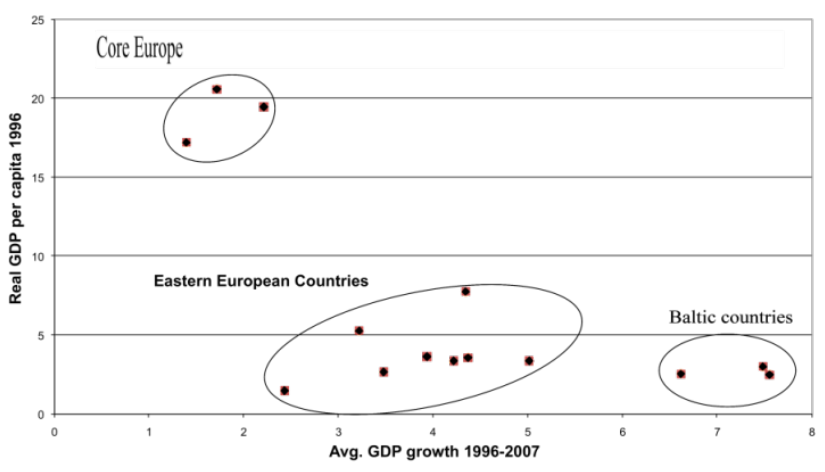

Figure 3. Convergence groups

\section{Data and Methodology}

Time series used in this study are: employment, real GDP, and capital stock. We also require real investment and long-term real interest rate on capital investments to compute an approximation for the initial level of capital stock. Data sources were National Accounts and other statistics gathered from Eurostat. Capital stock is measured through a perpetual inventory relation on a series of gross fixed domestic capital formation. We measure MFP as the Solow residual of a Cobb-Douglas functional form, which requires to determine the share of capital in GDP. Thus, our economy is described with the neoclassical production function:

$$
y_{t}=A_{t} k_{t}^{\alpha} N_{t}^{1-\alpha}
$$


where $y_{t}$ is real gross domestic product (GDP), $A_{t}$ is multi factor productivity (MFP), $k_{t}$ real capital stock, $N_{t}$ is the number of employed workers in the economy and $\alpha$ is the share of capital in GDP.

Equation (1) can be written in terms of growth rates as:

$$
\dot{y}=\dot{A}+\alpha \dot{k}+(1-\alpha) \dot{N},
$$

where dotted quantities denote annual growth rates. The stock of capital evolves according to the following law of motion:

$$
k_{t+1}=(1-\delta) k_{t}+i_{t},
$$

where $k_{t+1}$ is the stock of capital in period $\mathrm{t}+1, \delta$ is the depreciation rate of capital and $i_{t}$ is real investment.

The desired capital stock comes from equating the marginal rate of return on real capital to the user cost of capital and is equal to:

$$
M P K_{t+1}=\alpha A_{t+1}\left(\frac{N_{t+1}}{K_{t+1}}\right)^{1-\alpha}=r_{t}+r p_{t}+\delta
$$

where $r p_{t}$ is the default premium assessed by rational investors, that is the spread in the cost of capital between a country and the countries with minimal default risk.

To estimate MFP by inverting equation (1) we need to estimate the stock of capital in any given year recursively from equation (3), and to do so we need information about depreciation and the initial stock of capital.

While data on depreciation are standard from national income and product accounts, the measurement of the initial stock of capital can be estimated assuming, that the economy is in steady state at time zero, so that:

$$
K_{0}=\frac{\alpha}{r_{0}+\delta}
$$

Here $r_{0}$ is the real interest rate at time zero, $\delta$ is the rate of depreciation and $\alpha$ is the share of capital income in GDP. To obtain the range of initial values for the stock of capital we use, where available, long term real interest rates, while rates of depreciation are set at 5\% and $\alpha$ is quite stable around $30 \%$. It follows that the initial stock of capital of Eastern European countries lies between 0.8 and 2.0 times the value of real GDP in year zero.

We use non-parametric, linear programming technique DEA to measure and compare efficiency of decision-making units (DMUs). After identification of input-output variables, for a set of DMUs, the production possibility set (PPS), within which the DMUs operate, have to be implemented. The PPS contains all the correspondences of input and output vectors that are feasible in principle, even if not observed in practice. Once PPS is known, the location of a DMU within the PPS will tell us about its relative performance.

Given input-output data, technology can be represented by the PPS of feasible input-output combinations:

$$
T=[(x, y): x \text { can produce } y], \quad t=1, \ldots, T
$$

For purposes of efficiency measurement, the upper (efficient) boundary of $\mathrm{T}$ (the "frontier") is the locus of optimal production plans (i.e. the minimum achievable input level for a given output, or maximum achievable output given the level of the inputs). Such boundary is referred to as the (reference) technology frontier. Technically inefficient DMUs operate at points in the interior of $\mathrm{T}$, while those that are technically efficient operate somewhere along the frontier.

For any given firm i observed in two periods, $\mathrm{t}=1,2\left(x_{i}{ }^{l}, y_{i}{ }^{l}\right)$ and $\left(x_{i}^{2}, y_{i}^{2}\right)$, and using $\mathrm{t}=1$ as benchmark technology, a valid representation of the technology is given by Shephard's output distance function, which measures the maximum possible output that a given amount of inputs can produce:

$$
\mathrm{D}(\mathrm{x}, \mathrm{y})=\min [\theta:(\mathrm{x}, \mathrm{y} / \theta) \in \mathrm{T}]
$$

Here we note that when $\theta$ is minimised, $y / \theta$ is maximised. $\mathrm{D}(\mathrm{x}, \lambda \mathrm{y})$ is also homogeneous of degree 1 in outputs, since $D(x, \lambda y)=\lambda D(x, \lambda y), \lambda>0$ and non increasing in $\mathrm{x}$.

If distance function $D(x, y)=1$, the evaluated DMU is said to be efficient, representing the best practice technology, while if $D(x, y)<1$, the evaluated DMU is said to be inefficient, in that for the observed input level $\mathrm{x}$, the output vector y could be expanded within the production technology. Further, if technology exhibits global or local constant returns to scale, that is, if technology is linearly homogeneous, that is $(x, y) \in T \Rightarrow(\lambda x, \lambda y) \in T$ for all $\lambda>0$, then the output distance function is homogeneous of degree -1 in inputs and any Malmquist index based on a constant returns to scale technology is a productivity index.

As a generalization of the production function to multiple outputs, the Shephard output distance function allows us to aggregate inputs and outputs. Caves, Christensen and Diewert, CCD, (1982a) first introduced the Malmquist index (MI) as the ratio between two distance functions that compares a firm's productivity with that of an alternative firm over time. Hence, MI compares observed input-output bundles to a given reference technology. Initially, CCD conceived MI as a purely theoretical index: in order to use it for empirical purposes, knowledge of parameters and the specification of functional form for production was needed.

Nishimizu and Page (1982) used the frontier production function model developed by Aigner and Chu (1968) to get an empirical application of the Malmquist Productivity Index and later, Fare, Grosskopf, Lindgren and Roos (1994) showed that MI could be empirically implemented also by means of Data Envelopment Analysis, DEA, techniques. Both applications led to a decomposition of MI into technological change and efficiency change as separate components of productivity change, when allowing for inefficient production processes. However, the definition of Malmquist Index was based on a technological restriction, namely a constant returns to scale technology, thus ignoring the contribution of scale change to productivity change. The idea can be shown graphically by a simplified (one-input and one-output with constant returns to scale (CRS) technology) case. 


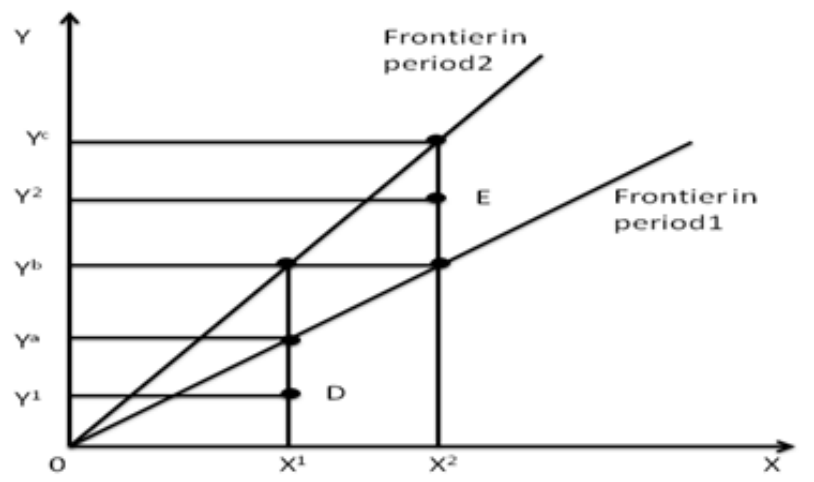

Figure 4. Decomposition of the Malmquist Productivity Index

Points $\mathrm{D}$ and $\mathrm{E}$ in Figure 4 represent the input-output combinations of a production unit in periods 1 and 2 respectively. In both cases, the firm is operating below the production possibility frontier. In period 1 (correspondingly, period 2), with input $x^{1}\left(x^{2}\right)$, it should be able to produce $\mathrm{y}^{\mathrm{a}}$ $\left(\mathrm{y}^{\mathrm{c}}\right)$ if it has full technical efficiency. Then the technical efficiency is measured by $y^{l} / y^{a}\left(y^{2} / y^{c}\right)$.

Productivity change can be measured by the part of output growth that is not contributed by input growth. From Figure 4 , we can calculate a productivity index by $\left(y^{2} / y^{l}\right) /\left(y^{b} / y^{a}\right)$, where $\left(y^{2} / y^{l}\right)$ is the output growth and $\left(y^{b} / y^{a}\right)$ represents a movement along the production frontier in period 1 . This can be rewritten as $\left(y^{2} / y^{b}\right) /\left(y^{l} / y^{a}\right)$, where the numerator is a distance function for output in period $2\left(y^{2}\right)$ with reference to the technology of period 1 and the denumerator is the distance function representing technical efficiency in period 1. This is precisely the Malmquist Productivity Index defined by $\mathrm{CCD}$, with reference to the technology of the initial period:

$$
M_{C C D}^{1}=\frac{D^{1}\left(x_{i}^{2}, y_{i}^{2}\right)}{D^{1}\left(x_{i}^{1}, y_{i}^{1}\right)}
$$

where $D^{l}\left(x_{i}^{2}, y_{i}^{2}\right)$ represents a distance function which compares second period firms to the base period technology However, we can also choose the technology in period 2 as the reference in defining a productivity index. The Malmquist Productivity Index in relation to the technology of the final period can be defined as:

$$
M_{C C D}^{2}=\frac{D^{2}\left(x_{i}^{2}, y_{i}^{2}\right)}{D^{2}\left(x_{i}^{1}, y_{i}^{1}\right)}
$$

The two indexes appear to be identical in the simple case represented by Figure 4. However, they may or may not be the same in the cases of multiple inputs and varying returns to scale (VRS) technology. To avoid the arbitrariness in choosing the benchmark, Färe et al. (1994) specify the Malmquist Productivity Index as the geometric mean of those two Malmquist productivity indexes based on benchmark technology from different periods (1 and 2):

$$
M_{C C D}=\left[\frac{D^{1}\left(x_{i}^{2}, y_{i}^{2}\right)}{D^{1}\left(x_{i}^{1}, y_{i}^{1}\right)} * \frac{D^{2}\left(x_{i}^{2}, y_{i}^{2}\right)}{D^{2}\left(x_{i}^{1}, y_{i}^{1}\right)}\right]^{\frac{1}{2}}
$$

Values of such index, $M_{C C D}$ greater than 1 would be verified in the presence of technical progress; if $M_{C C D}=1$ stagnation has occurred between periods 1 and 2, while if $M_{C C D}<1$, a decline of productivity occurred.

When multiple input - multiple output production set are considered, the Malmquist index becomes a productivity index which must satisfy, among others, a proportionality axiom. If outputs are to be increased in the same proportion from one period to the next (while inputs remain the same), then the productivity index is to increase in the same proportion, Førsund (1997). Correspondingly, if inputs are reduced in the same proportion while outputs remain the same, then the productivity index should increase in such proportion. As far as the Malmquist productivity index is concerned, the proportionality property requires that the distance functions should be linearly homogeneous of degree +1 in outputs and -1 inputs, with constant returns to scale for the benchmark technology.

In order to ensure that a Malmquist productivity index would satisfy the desirable homogeneity properties in outputs and inputs while keeping the fairly reasonable assumption of variable returns to scale on technology, an adequate definition of distance functions is needed, so as to compare productive performance to a benchmark technology, which is linearly homogeneous, thus including both technical and scale efficiency. Again, a distance function that encompasses technical and scale efficiency is equivalent to the linear homogeneous technology based on a Shephard's output distance function. Balk (2001) showed how such distance function is able to measure efficiency against firms operating at the most productive scale sizes and whose productions processes imply local constant returns to scale. This distance function corresponds to:

$$
\bar{D}(x, y)=\min [\vartheta>0:(x, y / \bar{\vartheta}) \in T]
$$

which is a measure of productive efficiency that compares a firm's observed productivity to the highest productivity level which corresponds to the highest scale elasticity. When no productivity gains are feasible $D(x, y)=1$, while $D(x, y)<1$ when the firm is productively inefficient and productivity gains can be achieved by increasing technical efficiency, scale efficiency, or both.

\section{Decomposition of Malmquist Productivity Index}

Several decompositions of the Malmquist productivity index have been proposed in order to provide all relevant information regarding technological and efficiency change, and whose terms can be interpreted in an meaningful manner.

Färe, Grosskopf, Lindgren and Roos (1994) showed that the contribution of technical progress to (10) can be disentangled through the following decomposition: 


$$
M_{F G L R}=\frac{D^{2}\left(x_{i}^{2}, y_{i}^{2}\right)}{D^{1}\left(x_{i}^{1}, y_{i}^{1}\right)}\left[\frac{D^{1}\left(x_{i}^{2}, y_{i}^{2}\right)}{D^{2}\left(x_{i}^{2}, y_{i}^{2}\right)} * \frac{D^{2}\left(x_{i}^{2}, y_{i}^{2}\right)}{D^{2}\left(x_{i}^{1}, y_{i}^{1}\right)}\right]^{\frac{1}{2}}=T E C^{1,2} T C^{1,2}
$$

where the ratio outside the brackets measures the change in technical efficiency between period 1 and 2 . The geometric mean of the two ratios inside the square brackets captures the shift in technology between the two periods evaluated at $x^{l}$ and $x^{2}$.

Those two components of the Malmquist Index as represented in Figure 4, are:

$$
\text { TEC1,2 }=\text { Efficiency change }=\frac{y^{2} / y^{c}}{y^{1} / y^{a}}
$$

and

$$
\text { TC1,2 }=\text { Technical change }=\left[\frac{y^{2} / y^{b}}{y^{2} / y^{c}} \times \frac{y^{1} / y^{a}}{y^{1} / y^{b}}\right]^{1 / 2}
$$

While $\mathrm{TEC}^{1,2}$ measures the change in relative efficiency, that is the gap of observed production from maximum potential production, thus identifying movements toward the frontier (i.e. catching up), $\mathrm{TC}^{1,2}$ captures the shift in technology between the two periods with regard to the actual best practice frontier.

TEC $^{1,2}$ compares how a given firm varies its productive performance in time with regard to the base period technology; if technical efficiency increases, $\mathrm{TEC}^{1,2}>1$, so that the change in productivity outgrows technological change and the DMU gets closer to the production frontier. Another situation arises when the DMU gets closer to the base period best practice frontier $\left(\mathrm{M}_{\mathrm{CCD}}>1\right)$ but contemporarily the production frontier experiences technical progress $\left(\mathrm{TC}^{1,2}>1\right)$; now, either the technological change outgrows the change in productivity $\left(\mathrm{TEC}^{1,2}<1\right)$ or the productivity gain from increasing technical efficiency is exactly offset by technical progress and there is no change in technical efficiency $\left(\mathrm{TEC}^{1,2}=1\right)$.

However, estimation of technical change has been found computationally difficult, since the index does not satisfy the proportionality property (it is not homogeneous of degree -1 in inputs), hence Fare, Grosskopf, Lindgren and Roos (1994) defined a similar index, by considering the distance function (11) relative to a constant returns to scale technology, which would render the Malmquist index a productivity index, as a change in the ratio of average products in adjacent periods:

$$
\bar{M}_{F G L R}=\frac{\bar{D}^{2}\left(x_{i}^{2}, y_{i}^{2}\right)}{\bar{D}^{1}\left(x_{i}^{1}, y_{i}^{1}\right)}\left[\frac{\bar{D}^{1}\left(x_{i}^{2}, y_{i}^{2}\right)}{\bar{D}^{2}\left(x_{i}^{2}, y_{i}^{2}\right)} * \frac{\bar{D}^{2}\left(x_{i}^{2}, y_{i}^{2}\right)}{\bar{D}^{2}\left(x_{i}^{1}, y_{i}^{1}\right)}\right]^{\frac{1}{2}}=E C^{1,2} * P T C^{1,2}
$$

Now the technical change term yields potential productivity change between firms that operate at the most productive scale sizes - where firms are technical and scale efficient - in two consecutive periods, i.e. PTC ${ }^{1,2}$ may be viewed as the highest productivity change in the absence of inefficiency and it would only correctly measure "technical change when constant returns to scale hold", as Ray and Desli (1997) suggest. On the other hand, equal reasoning applies to the efficiency change term, which now measures how far a firm is from the benchmark constant returns to scale productivity, and therefore comprises both technical and scale efficiency change terms.

Scale efficiency change, that is any productivity differential due just to a suboptimal scale, can be measured by an index such as:

$$
S E^{1}=\frac{\bar{D}^{1}\left(x_{i}^{1}, y_{i}^{1}\right)}{D^{1}\left(x_{i}^{1}, y_{i}^{1}\right)}
$$

where the denominator represents a technical efficiency measure which reflects how far is the evaluated firm from the best practice technology (which includes technical efficiency only) and the numerator reflects how far it is from the highest productivity represented by the constant returns to scale technology (which includes both technical and scale efficiency). Hence scale efficiency compares the highest productivity attained at actual scale to the highest productivity observed at optimal scale.

By comparing scale efficiency in consecutive periods, we get a measure of how a firm's changes its productive performance from a scale perspective when technology's optimal scale changes:

$$
S E C^{1,2}=\frac{\bar{D}^{2}\left(x_{i}^{2}, y_{i}^{2}\right)}{D^{2}\left(x_{i}^{2}, y_{i}^{2}\right)} / \frac{\bar{D}^{1}\left(x_{i}^{1}, y_{i}^{1}\right)}{D^{1}\left(x_{i}^{1}, y_{i}^{1}\right)}
$$

Moving from $t$ to $t+1$ a firm can improve its productive performance making use of the returns to scale offered by the best practice technology, while at the same time the nature of the best practice technology also changes from one period to the next.

Following the methodology of the technical efficiency change case, scale efficiency can be decomposed as:

$$
\begin{aligned}
& \operatorname{SEC}^{1,2}=\frac{\bar{D}^{1}\left(x_{i}^{2}, y_{i}^{2}\right) / D^{1}\left(x_{i}^{2}, y_{i}^{2}\right)}{\bar{D}^{1}\left(x_{i}^{1}, y_{i}^{1}\right) / D^{1}\left(x_{i}^{1}, y_{i}^{1}\right)} / \frac{\bar{D}^{1}\left(x_{i}^{2}, y_{i}^{2}\right) / D^{1}\left(x_{i}^{2}, y_{i}^{2}\right)}{\bar{D}^{2}\left(x_{i}^{2}, y_{i}^{2}\right) / D^{2}\left(x_{i}^{2}, y_{i}^{2}\right)} \\
& =\text { RTS }^{1} / \operatorname{STC}^{1,2}
\end{aligned}
$$

where returns to scale $R T S^{l}$ represent variations of productivity which follow a change in the DMU's scale with respect to the base technology, while $S T C^{1,2}$ represents variations of scale efficiency when a change in the technology is measured with regard to the comparison period firm, i.e. the scale -bias - of technical change.

Thus, if $R T S^{l}>1$, the firm improves its performance with regard to the base period productivity benchmark by exploiting increasing returns to scale and getting closer to the most productive scale size, if instead $R T S^{l}<$ input change carries decreasing returns to scale and the firm is moving away from optimal scale. Finally, when $R T S^{l}=1$, the firm does not profit from scale economies as when constant returns to scale prevail over the input range.

The scale -bias- of technical change, $S T C^{1,2}$, shows whether any productivity gain (loss) due to the effect of 
increasing (decreasing) returns to scale with respect to the benchmark technology, finally results in a scale efficiency gain or not. By jointly taking into account technical change and the scale - bias of technical change to determine potential productivity change over time from a given firm perspective, i.e. productivity change at the reference optimal scale, it is possible to decompose this term $\left(P T C^{l, 2}\right)$ in the following way:

$$
\begin{aligned}
& \operatorname{PTC}^{1,2}=\frac{\bar{D}^{1}\left(x_{i}^{2}, y_{i}^{2}\right)}{\bar{D}^{2}\left(x_{i}^{2}, y_{i}^{2}\right)}=\frac{D^{1}\left(x_{i}^{2}, y_{i}^{2}\right)}{D^{2}\left(x_{i}^{2}, y_{i}^{2}\right)} \frac{\bar{D}^{1}\left(x_{i}^{2}, y_{i}^{2}\right) / D^{1}\left(x_{i}^{2}, y_{i}^{2}\right)}{\bar{D}^{2}\left(x_{i}^{2}, y_{i}^{2}\right) / D^{2}\left(x_{i}^{2}, y_{i}^{2}\right)} \\
& =T C^{1,2} * S T C^{1,2}
\end{aligned}
$$

Potential productivity change at optimal scale can be decomposed into technical change weighted by a bias against or in favour of the reference firm input scale. If $S T C^{1,2}>1$, productivity gain reflected by technical change at the comparison period input scale does not match the potential productivity change observed at optimal scale, and accordingly, technical change at the firms' scale has to be augmented with an additional productivity gain if it is to match that one at optimal scale. Therefore, we can conclude that the change in the technology with regard to optimal scale presents a bias against the reference input scale. Contrarily, when $S T C^{1,2}<1$, productivity change at the reference input scale exceeds productivity change at optimal scale, and consequently technical change has to be lowered in the amount necessary to match productivity change at optimal scale. Therefore, the change in the technology with regard to optimal scale presents a bias in favour of the reference input scale. Finally, $S T C^{l, 2}=1$ shows how the scale bias of technical change is neutral since productivity change at the reference input scale matches productivity change at optimal scale, as would be the case in the presence of constant returns to scale.

Let us now interpret the alternative values of the scale bias of technical change with respect to returns to scale and their net result regarding scale efficiency change. From a geometric mean perspective, if $S T C^{1,2}>1$, the scale bias of technical change works against the reference input scales and any productivity gain due to increasing returns to scale, $R T S^{l}>1$ would be counterbalanced. Therefore, there is scale efficiency gain if $R T S^{l}>S T C^{l, 2}$ and vice versa. On the other hand, if the firm undergoes decreasing returns to scale from the base to the comparison period, productivity loss is reinforced and the firm losses scale efficiency. When $S T C^{1,2}<1$, the scale bias of technical change works in favour of the reference input scale. Hence, if the firm experiences decreasing returns to scale when moving from the first to the second period, this productivity loss would be offset by the scale bias of technical change and the final result on scale efficiency change once again depends on their relative values. If the firm enjoys increasing returns to scale, the scale bias of technical change reinforces such productivity gain. Finally if $S T C^{1,2}=1$, technical change at the reference and optimal inputs scales coincide, and any change in scale efficiency is exclusively given by the nature of returns to scale as the scale bias of technical change is neutral.

Following FGLR (1992) decomposition, FGNZ (1994) proposed a different framework, which takes into account a scale efficiency component. Considering its geometric mean definition, it is equal to:

$$
\begin{aligned}
& \bar{M}_{F G N Z}=\left[\frac{\bar{D}^{1}\left(x_{i}^{2}, y_{i}^{2}\right)}{\bar{D}^{1}\left(x_{i}^{1}, y_{i}^{1}\right)} * \frac{\bar{D}^{2}\left(x_{i}^{2}, y_{i}^{2}\right)}{\bar{D}^{2}\left(x_{i}^{1}, y_{i}^{1}\right)}\right]^{\frac{1}{2}}= \\
& {\left[\frac{\bar{D}^{1}\left(x_{i}^{2}, y_{i}^{2}\right)}{\bar{D}^{2}\left(x_{i}^{2}, y_{i}^{2}\right)} * \frac{\bar{D}^{1}\left(x_{i}^{1}, y_{i}^{1}\right)}{\bar{D}^{2}\left(x_{i}^{1}, y_{i}^{1}\right)}\right]^{\frac{1}{2}} \frac{D^{2}\left(x_{i}^{2}, y_{i}^{2}\right)}{D^{1}\left(x_{i}^{1}, y_{i}^{1}\right)} \frac{\bar{D}^{2}\left(x_{i}^{2}, y_{i}^{2}\right) / D^{2}\left(x_{i}^{2}, y_{i}^{2}\right)}{\bar{D}^{1}\left(x_{i}^{1}, y_{i}^{1}\right) / D^{1}\left(x_{i}^{1}, y_{i}^{1}\right)}=} \\
& P T C^{1,2} * T E C^{1,2} * S E C^{1,2}
\end{aligned}
$$

Here, productivity change may be decomposed into a potential productivity change at optimal scale, an efficiency change component defined relative to the VRS (best practice) technology and a scale efficiency change component which is the ratio of scale efficiency in period 1 and 2 and that expands output up to most productive or efficient scale, which leaves a technical change term evaluated at most productive scale size.

Ray and Desli (1997) proposed a further decomposition, which measures the contribution of best practice technical change $T C_{o}^{1,2}$, technical efficiency change $T E C_{o}^{1,2}$ and returns to scale $R T S_{o}{ }^{1,2}$ as:

$$
\begin{aligned}
& \bar{M}_{R D}=\left[\frac{\bar{D}^{1}\left(x_{i}^{2}, y_{i}^{2}\right)}{\bar{D}^{1}\left(x_{i}^{1}, y_{i}^{1}\right)} * \frac{\bar{D}^{2}\left(x_{i}^{2}, y_{i}^{2}\right)}{\bar{D}^{2}\left(x_{i}^{1}, y_{i}^{1}\right)}\right]^{\frac{1}{2}}= \\
& {\left[\frac{D^{1}\left(x_{i}^{2}, y_{i}^{2}\right)}{D^{2}\left(x_{i}^{2}, y_{i}^{2}\right)} * \frac{D^{1}\left(x_{i}^{1}, y_{i}^{1}\right)}{D^{2}\left(x_{i}^{1}, y_{i}^{1}\right)}\right]^{\frac{1}{2}} \frac{D^{2}\left(x_{i}^{2}, y_{i}^{2}\right)}{D^{1}\left(x_{i}^{1}, y_{i}^{1}\right)}} \\
& {\left[\frac{\bar{D}^{1}\left(x_{i}^{2}, y_{i}^{2}\right) / D^{1}\left(x_{i}^{2}, y_{i}^{2}\right)}{\bar{D}^{1}\left(x_{i}^{1}, y_{i}^{1}\right) / D^{1}\left(x_{i}^{1}, y_{i}^{1}\right)} \frac{\bar{D}^{2}\left(x_{i}^{2}, y_{i}^{2}\right) / D^{2}\left(x_{i}^{2}, y_{i}^{2}\right)}{\bar{D}^{2}\left(x_{i}^{1}, y_{i}^{1}\right) / D^{2}\left(x_{i}^{1}, y_{i}^{1}\right)}\right]=} \\
& T C^{1,2} * T E C^{1,2} * R T S^{1,2}
\end{aligned}
$$

How to choose between FGNZ (20) and RD (21)? Apart from disputes in literature about the inclusion $P T C_{o}{ }^{1,2}$ rather $T C_{o}^{1,2}$ or $S E C_{o}^{1,2}$ rather than $R T S_{o}^{1,2}$, there seems to be a trade off between technical change and scale efficiency change. If one supports a decomposition that includes the accepted notion of effective technical change at the firms input scale -and not potential productivity change at optimal scale-, then one gives up a scale efficiency change term but takes in a returns to scale component. While RD (21) provides an accurate decomposition of productivity change taking into account firm's input scale for measuring both technical change and returns to scale, in FGNZ (20), this desirable relationship between scale and productivity change coming from technical change is lost, but additional information regarding technological and efficiency changes is given, i.e. potential productivity change and scale efficiency change are now explicitly considered.

However both proposals are interrelated, since $S E C^{l, 2}=$ $R_{T S}^{l} / S T C^{l, 2}$ and $P T C^{l, 2}=T C^{l, 2} * S T C^{l, 2}$. Therefore, the 
scale -bias- of technical change $S T C^{1,2}$ links both decompositions, rendering possible a complete characterization of productivity change both from a technological -best practice- and efficiency perspective. Including $S T C^{l, 2}$ in the Malmquist productivity index decomposition would allow immediate access to all components that have been proposed in the literature. The question is whether it is possible to suggest a decomposition which includes the scale -bias- of technical change. Simar and Wilson (1998) introduced such decomposition. Their proposal can be obtained from both formulations. One may replace the potential contribution of productivity change at optimal scale in (20) by that of the effective contribution of technical change -productivity change of the benchmark technology at the firm's input scale- weighted by the scale -bias- of technical change -how productivity change at optimal scale shows a bias against or in favour of the firm's input scale, i.e. $P T C^{l, 2}=T C^{l, 2} * S T C^{l, 2}$. Alternatively, one may replace the effective contribution of returns to scale -how a firm profits from local increasing returns or endures local decreasing returns that materialize in higher or lower productivity change- by their counterpart in the form of the effective contribution of scale efficiency change -the movement of the firm toward or away from technically optimal scale in both periods- weighted by the scale -biasof technical change, i.e. $R T S^{l}=S E C^{l, 2} * S T C^{l, 2}$. Proceeding in either way, one obtains:

$$
\bar{M}_{S W}=T C^{1,2} * T E C^{1,2} * S E C^{1,2} * S T C^{1,2}
$$

By jointly looking at scale efficiency change and the scale -bias- of technical change, we can obtain relevant information with regard to returns to scale. If the firm gains scale efficiency from the base to the comparison period, $S E C^{l, 2}>1$, while the scale bias of technical change works against the firm's reference input $\operatorname{scaleSTC}_{o}{ }^{1,2}>1$, this outcome is only possible if returns to scale make a positive contribution to productivity change, $R T S^{1,2}>1$ a contribution which is larger than the unfavourable change in the scale bias of technical change. On the other hand, if a scale efficiency gain is accompanied by a favourable scale change of the technology, $S T C^{l, 2}<1$, then the presence of increasing returns to scale reinforces such scale efficiency gains. Alternatively, if decreasing returns to scale reduce productivity change, $R T S^{1,2}<1$, then scale efficiency gains are still possible as long as the favourable scale -bias- of technical change is not counterbalanced by those lowering returns, $R T S^{1,2}>S T C^{1,2}$ where both terms are smaller than one. In both cases the final outcome would be $S E C^{1,2}=R T S^{1,2} / S T C^{l, 2}>1$ and an opposite discussion may be presented when scale efficiency change reduces $S E C^{1,2}=R T S^{1,2} / S T C^{1,2}<1$. As Simar and Wilson (1998) remark, all this information would be lost if one settles for (11), because one would know the contribution of returns to scale to productivity change, but would not know if such contribution finally results in scale efficiency gain or not, neither if the change experienced by optimal scale works against or in favour of the firm's reference scale.

\section{Results}

The growth process of transition countries actually shows a considerable variation through time, hence we split the sample into two sub-periods: 1996-2001 and 2002-2007. During the first period, most countries were experiencing macroeconomic shocks while, at the same time, heavy privatisation and reorientation of trade were at work; the second period, showed greater macroeconomic stability and renewed efforts to implement the required structural reforms. Starting from Malmquist productivity index and its decomposition into efficiency and technical changes, we calculate average percentage growth rates between two points in time, $t_{1}$ and $t_{2}>t_{1}$, according to standard formulas ( $\triangle \mathrm{M}, \Delta \mathrm{EF}, \Delta \mathrm{TP})$, whereas $\Delta \mathrm{GDPW}$ represents the changes of real GDP per worker.

As already noted, over the whole sample period, we observe that the labour productivity measure $(\Delta \mathrm{GDPW})$ shows the highest values for the Baltic countries, while mean labour productivity growth of other Eastern European countries is much lower. The multi factor productivity pattern is entirely reversed, with Eastern European countries showing a positive growth of $\Delta \mathrm{M}$ measure and Baltic countries a negative one. Such reversal of results could be explained if we think that the Malmquist-based growth rates take into account the pace of capital accumulation, while $\triangle$ GDPW is based on a pure labour productivity measure.Table 2 shows that growth rates of Eastern European countries and Baltic countries are mainly due to a capital deepening process rather to effects of innovation. To shed further light on this, we obtained indicators of technological progress and change of technological efficiency, through the decomposition of the Malmquist productivity index in both subperiods. For the first subperiod, higher labour productivity of Baltic countries appear to be combined with decreasing productivity, mainly due to a lack of efficiency. During the second subperiod, however, as Baltic countries capital stock and labour force both gain speed with respect to eastern neighbours, MFP is much lower, following the decreasing pattern of technical progress. On the whole, Baltic countries growth rates seem to be driven by labour and capital growth rather than by gains in efficiency or technological catch-up.

Growth in multi-factor productivity, as derived from a gross output based production function, seems to be crucial for the pace of convergence over the medium to long term perspective. However, some analysis needs to be added in order to assess the absolute and conditional convergence process of the EU accession countries. 
Table 2. Productivity changes (average percentage growth rates)

\begin{tabular}{|c|c|c|c|c|c|c|c|c|c|c|c|c|}
\hline & \multicolumn{3}{|c|}{ Productivity } & \multicolumn{3}{|c|}{ Efficiency } & \multicolumn{3}{|c|}{ Technology } & \multicolumn{3}{|c|}{ Labour productivity } \\
\hline & \multicolumn{3}{|c|}{$\Delta \mathrm{M}$} & \multicolumn{3}{|c|}{$\Delta \mathrm{EF}$} & \multicolumn{3}{|c|}{$\Delta \mathrm{TP}$} & \multicolumn{3}{|c|}{$\Delta \mathrm{GDPW}$} \\
\hline & $\begin{array}{l}1996- \\
2007 \\
\end{array}$ & $\begin{array}{l}1996- \\
2001 \\
\end{array}$ & $\begin{array}{c}2002- \\
2007 \\
\end{array}$ & $\begin{array}{l}1996- \\
2007 \\
\end{array}$ & $\begin{array}{l}\text { 1996- } \\
2001 \\
\end{array}$ & $\begin{array}{c}2002- \\
2007 \\
\end{array}$ & $\begin{array}{c}1996-2 \\
007 \\
\end{array}$ & $\begin{array}{l}1996- \\
2001 \\
\end{array}$ & $\begin{array}{l}2002- \\
2007 \\
\end{array}$ & $\begin{array}{l}1996- \\
2007 \\
\end{array}$ & $\begin{array}{l}1996- \\
2001 \\
\end{array}$ & $\begin{array}{l}2002- \\
2007 \\
\end{array}$ \\
\hline EEC & 1,12 & 3,14 & $-0,63$ & 2,24 & 2,59 & 2,35 & $-1,09$ & 0,54 & $-2,91$ & 2,79 & 2,94 & 2,74 \\
\hline $\mathrm{BC}$ & $-3,41$ & $-3,16$ & $-3,52$ & $-1,23$ & $-2,91$ & 0,22 & $-1,95$ & $-0,52$ & $-3,74$ & 5,24 & 5,80 & 4,97 \\
\hline $\mathrm{CE}$ & 0,16 & $-0,27$ & 0,63 & 1,04 & $-0,10$ & 2,39 & $-0,87$ & $-0,17$ & $-1,73$ & 4,25 & 3,80 & 4,87 \\
\hline
\end{tabular}

The hypothesis of convergence among countries has been usually tested with a three versions framework:

- Absolute $\beta$-convergence. Long run convergence in growth rate and income level across regions is achieved irrespectively of initial conditions. This implies that poor countries grow faster than rich countries and that the growth rate of real per capita GDP is negatively related to the initial level of real per capita GDP (which requires a significant negative coefficient on initial productivity levels without conditioning variables). Given beta-convergence, the dispersion of regional GDP per capita could also tend to decrease, in which case we have sigma-convergence, meaning that during the convergence process the income levels of countries tend to converge, especially if the initial conditions are very similar.

- Conditional convergence. According to the Solow-Swan neoclassical growth model, regions with similar structural characteristics converge to the same growth rate, although not necessarily at the same capital-labour ratio, independently of initial conditions. In this case, the growth rate is still negatively related to initial income, after inclusion of control factors which characterize the steady state growth path of GDP per capita.

- Club convergence. Regions with similar structural characteristics converge only if their initial conditions are similar as well. In this case neither absolute nor conditional convergence is observed.

Early studies testing the convergence hypothesis, beginning with Baumol (1986), were based on regression analysis (with or without conditioning variables); figure 5 shows data about the accession countries' initial levels of real GDP per capita in PPP terms vis-à-vis the average level of "core Europe" (France, Italy, Germany) and their average annual GDP growth. With the exception of Bulgaria and Ukraine, most of the countries are located according to the principle of unconditional convergence (Slovenia stands as an outlier in relative terms).

In order to assess the validity of the absolute convergence hypothesis, we first use a descriptive data analysis. The speed of convergence of the accession countries is shown in table 3, which compares the income levels convergence process of the accession countries between 1996 and 2007. The gap with Core Europe GDP levels progressively narrowed, especially for Baltic countries - Estonia 16,4\%, Lithuania $10,0 \%$, and Latvia $14,2 \%$. Slovenia showed a marked reduction of such gap $(14,3 \%)$ as well. The group of Eastern European countries also reduced the gap with EU average by 5 to $7 \%$, with the exception, once again, of Bulgaria.

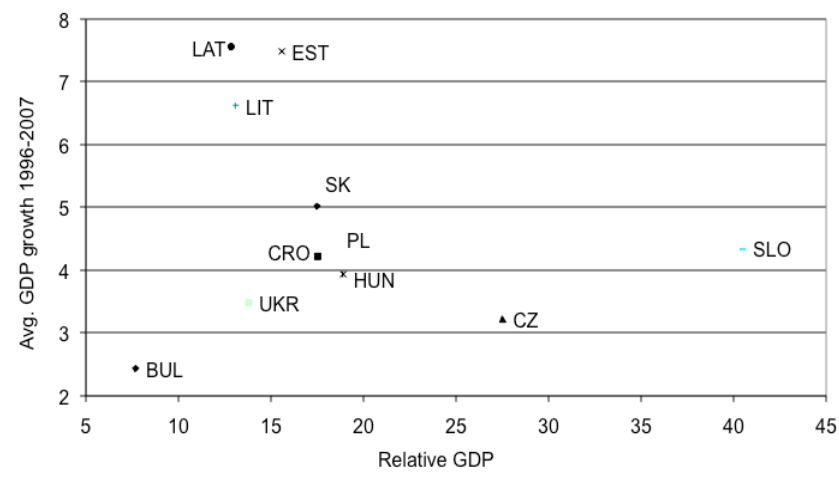

Figure 5. Accession countries' initial real GDP per capita levels in 1996 vis-à-vis the "Core Europe" level (in \%) and their average GDP growth in 1996-2007 [6]

Analysis of sigma ( $\sigma$ ) convergence shows that during the growth process, the income levels of transition countries did not become more equal, since the variation between their GDP levels per capita increases. In order to test these ideas, standard deviations were calculated for several subsets of countries, nonetheless showing that Eastern European countries grew at a much more similar pace than Baltic countries (which experienced no convergence within the group) in comparison with core Europe. Quah (1993, 1996a, 1997) criticized convergence results from regressions (or correlations) stating that analyses based on first moments of the distribution cannot adequately address the convergence issue, hence we refer to kernel measures of the international distribution of labour productivity over time, which have been successfully used for capturing (conditional) dependence of variables, especially in time series applications. 
Table 3. The accession countries' convergence with core European level

\begin{tabular}{|c|c|c|c|}
\hline & \multicolumn{2}{|c|}{ GDP convergence from CEC average* (\%) } & \multirow[t]{2}{*}{$\begin{array}{c}\text { Speed of convergence } 1996-2007 \text { reduction of } \\
\text { relative GDP }\end{array}$} \\
\hline & 1996-2001 & $2002-2007$ & \\
\hline Bulgaria & 7,4 & 9,3 & 2,7 \\
\hline Croatia & 18,3 & 21,0 & 5,1 \\
\hline Czech Republic & 26,4 & 29,6 & 5,3 \\
\hline Hungary & 17,9 & 26,9 & 6,6 \\
\hline Poland & 20,3 & 24,4 & 6,1 \\
\hline Slovakia & 14,6 & 22,1 & 6,7 \\
\hline Ukraine & 14,3 & 19,8 & 7,1 \\
\hline Slovenia & 19,9 & 22,6 & 14,3 \\
\hline Estonia & 42,7 & 50,3 & 16,4 \\
\hline Latvia & 17,9 & 21,0 & 14,2 \\
\hline Lithuania & 13,4 & 18,5 & 10,0 \\
\hline \multicolumn{4}{|c|}{$\sigma$-convergence ${ }^{* *}$} \\
\hline \multicolumn{2}{|c|}{ among Eastern European countries } & \multicolumn{2}{|r|}{54,7} \\
\hline \multicolumn{2}{|c|}{ among Baltic countries } & \multicolumn{2}{|r|}{252,1} \\
\hline \multicolumn{2}{|c|}{ among Core European countries } & \multicolumn{2}{|r|}{49,4} \\
\hline
\end{tabular}

* Average spread on growth rates

** Standard deviation of real Gdp per capita

In figure 6, the growth process of labour productivity doesn't reveal any tendency to reduce existing differences of the mean and the dispersion among all countries through time. Both the persisting dispersion and the presence of bimodality provide evidence against the convergence hypothesis. The latter, in particular, means that core European and Eastern European countries are still divided, as a stylized fact, into two categories: the rich and the poor ones. This phenomenon has been referred to in the literature as "two-club," or "twin-peak," convergence (that is "international polarization") in several contributions from Quah, Jones (1997) and Henderson and Russell (2005).

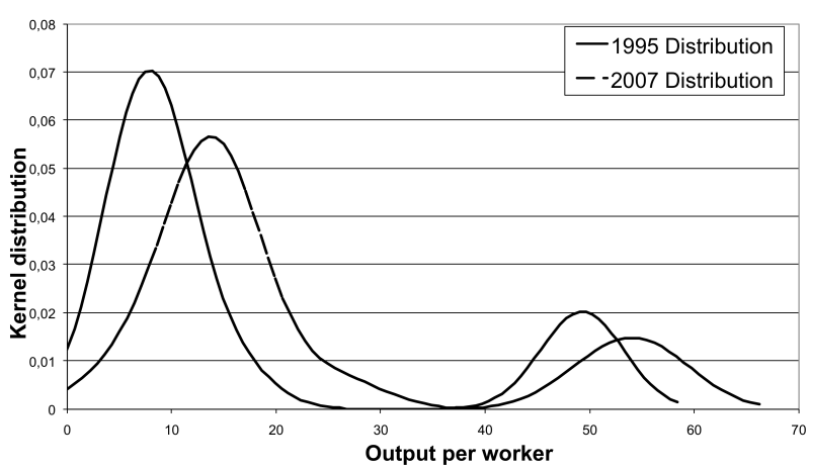

Figure 6. Distributions of labour productivity (1995-2007)

Differences among subgroups are also revealed from inspection of productivity index patterns. While Baltic countries didn't experienced any converging process towards core European countries (figure 7), although displaying an almost similar track, Eastern European countries showed a different pattern of productivity from Core European countries.

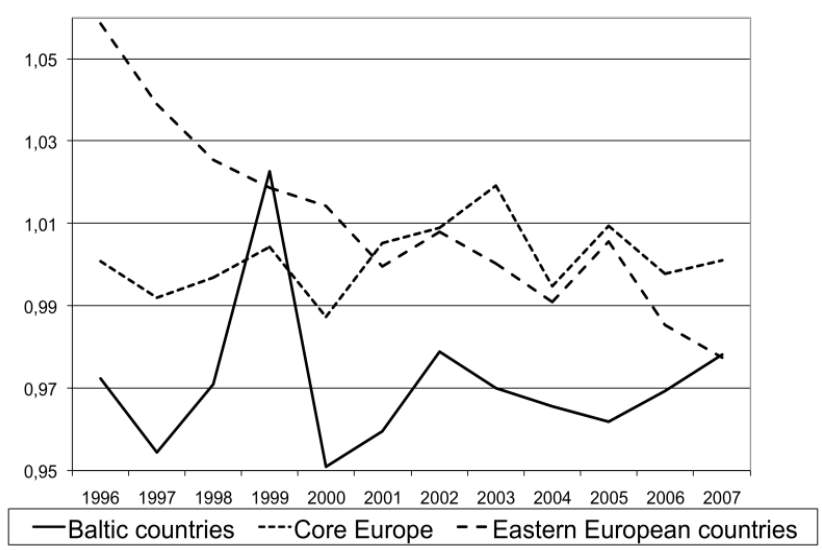

Figure 7. Malmquist Productivity Index

The convergence process among transition countries is rather evident, but the approach to Core Europe is not smooth over the long run and, what's more important, seems highly differentiated between the two main sources of productivity growth. The converging trend is apparently driven by technological progress rather than efficiency (figure 8 and 9). 


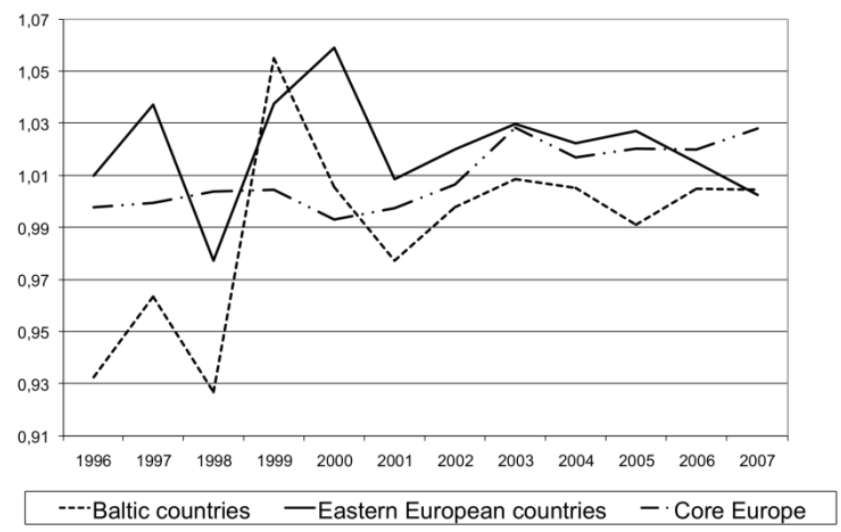

Figure 8. Efficiency change

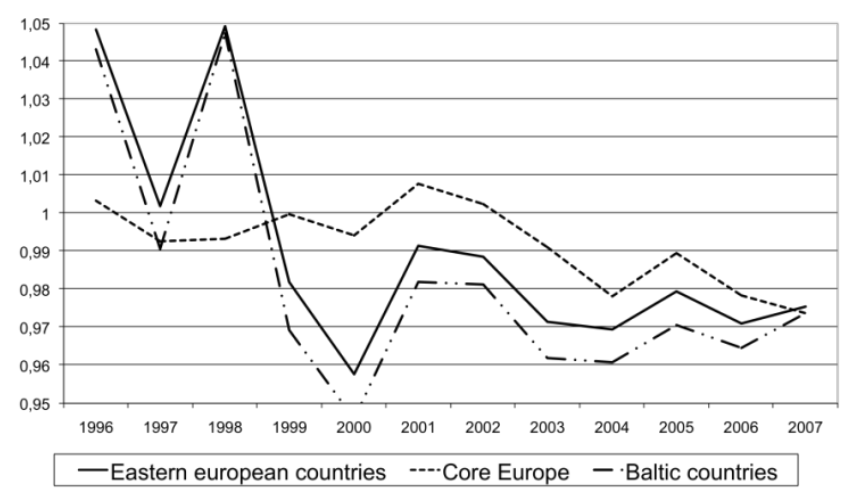

Figure 9. Technological progress

Before further decomposing the productivity index, we need to summarize the results obtained so far. Relative growth rates and kernel distribution point to the existence of distinct patterns of growth among different groups of countries. If a convergence process is at work, this runs through a closer connection between Baltic and Eastern European countries rather than between transition economies and Core European countries. However, the dynamics of productivity and technological progress for Eastern European countries might still drive them closer to Core Europe. On the contrary, Malmquist productivity index shows mixed results. A 1,02\% average productivity growth (Malmquist index from table 4) of Eastern European countries during the whole sample period stemmed from productivity gains during 1996-2001 (on average equal to $2,59 \%$ ) as combined with a decrease in productivity of 0,55\% over the 2001-2007 period. Core European countries experienced a much lower productivity gain over the entire period $(0,14 \%$ on average), but with a decrease in the first period $(-0,24 \%)$ counterbalanced by an increase in the second one $(+0,51 \%)$, while Baltic countries index of multi factor productivity shows a reduction of $2,88 \%$. On average, the contribution of technical progress has been very limited and, on the whole, negative $(-1,08 \%)$. Since potential productivity change is negative (in particular during the last five years) and less than average productivity, the catching up process between those countries seems at best negligible and equivalent to an efficiency gain of $0,072 \%$ per year. The slight increase in efficiency is almost entirely explained by technical improvements. The average efficiency gain is due to an equivalent increase of technical efficiency change TEC $(0,073 \%)$, showing how countries are getting closer on average to the best practice frontier, while the process toward optimal scale remains unaltered, since the average scale efficiency change index SEC is approximately equal to 1 .

The growth process of former centralized economies, led by a surge in real investments, has brought about technological improvements, but the transition to free markets still has to add the benefits of an increased efficiency. If the catching up process gets stronger through time, we could expect future improvements also on the efficient use of inputs, although the most recent path shows the existence of an efficiency gap with Core Europe (figure 10).

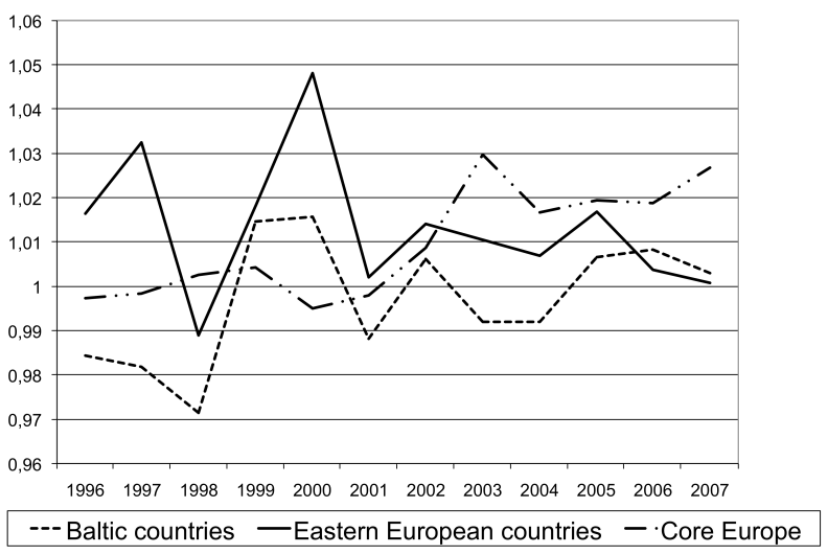

Figure 10. Technical efficiency change

Given the importance of the scale efficiency change component when explaining the annual $0,072 \%$ productive efficiency gain, it is important to determine what its sources are. Since SEC = RTS / STC, the converging process toward optimal scale is sustained by the relationship between the existence of decreasing returns to scale when considering the entire set of countries - since RTS $=0,9836$ - and the change in the scale of the technology. STC component represents the part of technical change that can be attributed to changes in output through exploitation of scale economies. In this regard, the scale-bias of technical change STC (how productivity change at optimal scale shows a bias against or in favour of the firm's input scale) represents the element which describes productivity change both from a technological -best practice- and efficiency perspective. If we consider subsets of countries, results change significantly. Core European countries show increasing returns to scale associated with equivalent STC values, so that scale efficiency remains constant through times. For Eastern European countries, the scale efficiency gain is accompanied by a scale change of the technology that works in favour of an increase in efficiency, since STC $<1$, but slightly decreasing returns to scale reduce productivity change, RTS $<1$. However, the scale efficiency gains are still present as long as the favourable scale-bias of technical change is not counterbalanced by those lowering returns. Lastly, Baltic 
countries, adapt their technology to decreasing returns to scale to benefit from an efficiency improvement during the last 5 years of our sample. On the whole, data show that Eastern European countries have best adapted their productive activities to existing scale economies, thus explaining the slight convergence to the frontier. It is now possible to turn our attention to the relevant sources responsible for the average productivity gain among each group of countries.

\section{Explaining MFP growth in Transition economies: Some Preliminary Results}

In this section we try to explain productivity growth through governance indicators and whether such determinants are common to all members countries. We use indicators from Worldwide Governance Indicators (WGI) research project, based on variables measuring perceptions of governance, as constructed by 32 different organizations from around the world. Six aggregate governance indicators are built in each period: Voice and Accountability, Political Stability and Absence of Violence/Terrorism, Government
Effectiveness, Regulatory Quality, Rule of Law, and Control of Corruption.

According to several authors, growth dynamics is related to measures of (excessive) regulations or to the effectiveness of the public sector in securing freedom to do business (van Ark, et al. 2008). Qualitative variables reflecting directly and indirectly government activity are used to assess relevance of such factors. Although our sample is not wide enough, we tentatively look for econometric evidence of correlation between MFP growth and a number of indicators published by the World Bank. We will present some evidence for econometric models of the form:

$$
\dot{T F} P=\alpha_{0}+\alpha_{1} \dot{T F} P_{-1}+\alpha_{2} \dot{X}_{i}+\alpha_{3} X_{i}+u_{i}
$$

where dotted variables stand for rates of growth, determinants X's are World Bank indicators described above and $u_{i}$ is the usual error term. Heteroskedastic consistent t-values are displayed with usual levels of significance. Also, an error correction term enters equations (except for Croatia and Slovak Republic) meaning that variables in levels may help capturing a kind of long term impact of those determinants on growth.

Table 4. The Malmquist Productivity Index and its decompositions. Geometric means

\begin{tabular}{|c|c|c|c|c|c|c|c|c|}
\hline \multicolumn{9}{|c|}{ All countries } \\
\hline & MALM & $\mathrm{EC}$ & PTC & TEC & SEC & $\mathrm{TC}$ & STC & RTS \\
\hline $1996-2007$ & 0,9960 & 1,0072 & 0,9892 & 1,0073 & 0,9998 & 1,0059 & 0,9839 & 0,9836 \\
\hline $1996-2001$ & 0,9982 & 0,9991 & 0,9996 & 1,0021 & 0,9968 & 1,0093 & 0,9906 & 0,9873 \\
\hline $2002-2007$ & 0,9938 & 1,0152 & 0,9789 & 1,0124 & 1,0028 & 1,0025 & 0,9772 & 0,9799 \\
\hline \multicolumn{9}{|c|}{ Eastern Europe (all countries) } \\
\hline & MALM & $\mathrm{EC}$ & PTC & TEC & SEC & $\mathrm{TC}$ & STC & RTS \\
\hline $1996-2007$ & 0,9907 & 1,0048 & 0,9865 & 1,0051 & 0,9996 & 1,0210 & 0,9665 & 0,9659 \\
\hline 1996-2001 & 0,9988 & 0,9991 & 1,0007 & 1,0052 & 0,9936 & 1,0220 & 0,9793 & 0,9726 \\
\hline $2002-2007$ & 0,9826 & 1,0106 & 0,9722 & 1,0050 & 1,0056 & 1,0201 & 0,9538 & 0,9592 \\
\hline \multicolumn{9}{|c|}{ Core Europe } \\
\hline & MALM & $\mathrm{EC}$ & PTC & TEC & SEC & $\mathrm{TC}$ & STC & RTS \\
\hline $1996-2007$ & 1,0014 & 1,0095 & 0,9920 & 1,0095 & 1,0000 & 0,9907 & 1,0013 & 1,0013 \\
\hline $1996-2001$ & 0,9976 & 0,9992 & 0,9984 & 0,9991 & 1,0001 & 0,9966 & 1,0019 & 1,0019 \\
\hline $2002-2007$ & 1,0051 & 1,0199 & 0,9855 & 1,0199 & 1,0000 & 0,9848 & 1,0007 & 1,0007 \\
\hline \multicolumn{9}{|c|}{ Eastern european countries } \\
\hline & MALM & $\mathrm{EC}$ & PTC & TEC & SEC & $\mathrm{TC}$ & STC & RTS \\
\hline $1996-2007$ & 1,0102 & 1,0204 & 0,9904 & 1,0132 & 1,0071 & 1,0019 & 0,9883 & 0,9952 \\
\hline $1996-2001$ & 1,0259 & 1,0215 & 1,0050 & 1,0177 & 1,0037 & 1,0083 & 0,9965 & 1,0001 \\
\hline $2002-2007$ & 0,9945 & 1,0193 & 0,9757 & 1,0087 & 1,0105 & 0,9956 & 0,9800 & 0,9903 \\
\hline \multicolumn{9}{|c|}{ Baltic countries } \\
\hline & MALM & $\mathrm{EC}$ & PTC & TEC & SEC & $\mathrm{TC}$ & STC & RTS \\
\hline 1996-2007 & 0,9712 & 0,9893 & 0,9826 & 0,9970 & 0,9921 & 1,0401 & 0,9447 & 0,9366 \\
\hline 1996-2001 & 0,9718 & 0,9767 & 0,9964 & 0,9927 & 0,9835 & 1,0357 & 0,9620 & 0,9452 \\
\hline $2002-2007$ & 0,9706 & 1,0019 & 0,9688 & 1,0013 & 1,0007 & 1,0445 & 0,9275 & 0,9281 \\
\hline
\end{tabular}

MALM = Malmquist productivity index, EC $=$ Efficiency change, $\mathrm{PTC}=$ Potential technical change, $\mathrm{TEC}=$ Technical efficiency change, $\mathrm{SEC}=$ Scale efficiency change, $\mathrm{TC}=$ Technical change, $\mathrm{STC}=$ Scale technology change, $\mathrm{RTS}=$ Returns to scale 
Table 5. Estimates of MFP growth

\begin{tabular}{|c|c|c|c|c|c|c|c|c|}
\hline & Bulgaria & Croatia & $\begin{array}{c}\text { Czech } \\
\text { Republic }\end{array}$ & Hungary & Poland & $\begin{array}{c}\text { Slovak } \\
\text { Republic } \\
\end{array}$ & Slovenia & Ukraine \\
\hline Constant & $-3,63 *$ & $6,024 * *$ & $-0,91 *$ & $-1,51$ & 0,566 & $-1,76 *$ & $-0,05$ & $-0,27$ \\
\hline Regulatory Quality $^{1}$ & 0,025 & $0,033 *$ & $0,101 * *$ & & 0,030 & & & \\
\hline Rule of Law ${ }^{1}$ & $0,016 *$ & & & & $0,060 *$ & $0,042 *$ & & \\
\hline Government Effectiveness ${ }^{1}$ & $0,010 *$ & & & & $0,050 *$ & & 0,011 & \\
\hline Control of Corruption ${ }^{1}$ & & 0,011 & & & & & & \\
\hline Political Stability ${ }^{1}$ & & & & 0,003 & & 0,032 & 0,023 & $0,013 *$ \\
\hline Voice \& Accountability & & $-13,6 *$ & & & & $0,049 *$ & & 0,027 \\
\hline Government Effectiveness & & & & 1,430 & & & & \\
\hline Rule of Law & & $29,70 *$ & & & & & & \\
\hline $\operatorname{MFP}^{1}(-1)$ & & & 0,082 & & & & & \\
\hline Error correction(-1) & $-105,5 *$ & & $-45,4 *$ & $-66,7 * *$ & $-97,9 *$ & & $-152, * *$ & $-101,6 *$ \\
\hline Adjusted R-squared & 0,82 & 0,84 & 0,71 & 0,17 & 0,53 & 0,44 & 0,80 & 0,58 \\
\hline Durbin-Watson & 2,78 & 2,73 & 1,97 & 2,00 & 2,02 & 2,68 & 1,60 & 2,62 \\
\hline
\end{tabular}

${ }^{1}$ growth rate

As expected, table 5 shows that implementation of policies fostering competition and freedom of entrepreneurial activities heavily affects productivity in the long run, given the clear significance of error correction coefficients. In general, MFP growth is mostly affected by a free market environment, as implemented through government policies. When sound regulatory policies and proper contract enforcement are implemented, firms may operate in a safer environment and improve their efficiency, while measures of government effectiveness and political stability are less relevant to entrepreneurial activities.

\section{Concluding Remarks}

In recent decades, a massive bulk of research has been devoted to investigation of the process of economic growth across European Union regions, and in particular in assessing the presence of convergence in regional growth rates. While the convergence process in European per capita income during 80's has been thoroughly proved, a number of studies have reported a slowdown of convergence thereafter (as in Gardiner et al. (2004), and Pittau (2005)). What happened to the convergence process is still under dispute. Empirical findings are mixed and strongly affected by differences in methodologies and data sets and both conditional and club convergence are still lively debated in the literature.

In this challenging intellectual framework, it is even hard to identify the "actual" force driving the growth process. In this paper we decided to comply with the idea of labor productivity as a main driver of regional growth. Gardiner et al. (2004), for example report that the degree of convergence in labor productivity has been disappointingly lower after the economic recovery during 80 's.

In our paper we have used efficiency analysis to shed more light on productivity growth and convergence of Eastern European countries towards the Euro area. Inefficient behaviour may result after decomposing labour productivity growth into technological change and efficiency gains. From 1996 to 2007, labour productivity shows higher values for Baltic countries with respect to other Eastern European countries, while the multi-factor productivity path is entirely reversed, with Eastern European countries showing a positive growth of MFP measure and Baltic countries a negative one. Such result could stem from the intense process of capital accumulation undergone by these economies and included in the Malmquist-based growth rates.

Further decomposing the Malmquist productivity index between technological progress and change of technological efficiency, shows that Baltic countries growth rates seem to be driven by labour and capital growth rather than by gains in efficiency or technological catch-up. This means that development policies aimed at promoting efficiency and technological progress, are mostly effective once the gaps in capital endowments have been reduced.

The convergence process also exhibits mixed evidence over the performance of transition economies. Labour productivity, Malmquist index and standard convergence regressions do not clearly state whether those countries do follow a common track towards the euro area. On the contrary, a twin-peak convergence process seems to emerge when adopting Kernel measures of productivity distribution over time. Analysis of the sources of productivity growth suggests that while technical progress may drive transition 
economies towards a common path, our panel of countries does not portray a common efficiency pattern. How countries adjust their production processes to existing scale economies seems to matter the most. Further evidence suggests that policy actions aimed at fostering MFP growth should mainly promote a competitive environment through sound regulation and proper enforcement measures.

\section{REFERENCES}

[1] D.J. Aigner, S.F. Chu. On Estimating The Industry Production Function, American Economic Review, Vol.58, pp. 826-839, 1968.

[2] B. Balk. Scale Efficiency and Productivity Change, Journal of Productivity Analysis, 15, 153-183, 2001.

[3] W.J. Baumol. Productivity Growth, Convergence, and Welfare: What the Long-run Data Show, American Economic Review, American Economic Association, vol. 76(5), pages 1072-85, December, 1986.

[4] D. Caves, L. Christensen, W. Diewert. The Economic Theory of Index Numbers and the Measurement of Input, Output and Productivity, Econometrica, 50:6, 1393-1414, 1982a.

[5] D. Caves, L. Christensen, W. Diewert. Multilateral Comparisons of Outputs, Input and Productivity Using Superlative Index Numbers, Economic Journal 92, 73-86, 1982b.

[6] Eurostat, 2013 Online available from http://epp.eurostat.ec.e uropa.eu

[7] R. Färe, S. Grosskopf, B. Lindgren, P. Roos. Productivity Developments in Swedish Hospitals: A Malmquist Output Approach in Data Envelopment Analysis: Theory, Methodology and Applications (Eds.) A. Charnes, W. Cooper, A. Lewin and L. Seiford, Dordrecht: Kluwer Academic Publishers, 1994.

[8] R. Färe, S. Grosskopf, D. Margaritis. Productivity Growth and Convergence in the European Union, Journal of Productivity Analysis 25(1), 111-141, 2006.

[9] R. Färe, S. Grosskopf, M. Norris, Z. Zhang. Productivity Growth, Technical Progress, and Efficiency Change in Industrialized Countries, American Economic Review, 84 (1), 66-83, 1994.

[10] F. Førsund. The Malmquist Productivity Index, TFP and Scale, Working Paper, Department of Economics and Business Administration, University of Oslo, 1997.

[11] H.O. Fried, C.A. Knox Lovell, S. Schmidt. The Measurement of Productive Efficiency and Productivity Growth, Oxford University Press, 2008

[12] B. Gardiner, R. Martin, P. Tyler P. Competitiveness, productivity and economic growth across the European regions, Regional Studies, 38,1045-1067, 2004

[13] I. Grosfeld, G. Roland. Defensive and Strategic Restructuring in Central European Enterprises, CEPR Discussion Papers 1135,1995
[14] "Governance Matters VII: Governance Indicators for 1996-2007." Further documentation and research using the WGI is available on the Resources page of this website or at www.worldbank.org/wbi/governance.

[15] D.J. Henderson,R.R. Russell. Human Capital and Convergence: A Production-Frontier Approach, International Economic Review, Vol. 46, No. 4, pp. 1167-1205, November 2005

[16] A. M. Kutan, T. M. Yigit. European Integration, Productivity Growth and Real Convergence, European Economic Review, 51(6), 1370-1395, 2007.

[17] A. M. Kutan, T. M. Yigit. European Integration, Productivity Growth and Real Convergence: Evidence from the New Member States, Economic Systems, 33(2), 127-137, 2009.

[18] C.I. Jones. On the Evolution of the World Income Distribution," Journal of Economic Perspectives, American Economic Association, vol. 11(3), pages 19-36, Summer, 1997.

[19] T. Mora, E. Vaya, J. Surinach. Specialisation and Growth: The Detection of European Regional Convergence Clubs, Economics Letters, 86(2), 181-185, 2005.

[20] M. Mrkaic. The Growth of Total Factor Productivity in Slovenia, Post-Communist Economies, Taylor and Francis Journals, vol. 14(4), pages 445-454, December, 2002.

[21] M. Novak. Empirics on Real Convergence within European Union: Is Growth in EU Sustainable?, International Journal of Sustainable Economy, 3(4), 455-473, 2011.

[22] M.G. Pittau. Fitting regional income distributions in the European Union, Oxford Bulletin of Economics and Statistics, 67, 135-161, 2005.

[23] D. Quah. Exploiting Cross Section Variation for Unit Root Inference in Dynamic Data, Papers 549, Stockholm International Economic Studies, 1993a.

[24] D. Quah.Galton's Fallacy and Tests of the Convergence Hypothesis, CEPR Discussion Papers 820, C.E.P.R. Discussion Papers, 1993b.

[25] D. Quah.Regional Convergence Clusters Across Europe," CEP Discussion Papers 0274, Centre for Economic Performance, LSE, 1996a.

[26] D. Quah.Twin Peaks: Growth and Convergence in Models of Distribution Dynamics, CEP Discussion Papers 0280, Centre for Economic Performance, LSE, 1996 b.

[27] D. Quah.Empirics for Growth and Distribution: Stratification, Polarization, and Convergence Clubs, CEPR Discussion Papers 1586, C.E.P.R. Discussion Papers, 1997.

[28] M. Salinas-Jimenez, I. Alvarez-Ayuso, J. Delgado-Rodriguez. Capital accumulation and TFP growth in the EU: A production frontier approach, Journal of Policy Modeling 28, 195-205, 2006.

[29] S. Ray, E. Desli. Productivity Growth, Technical Progress, and Efficiency Change in Industrialized Countries: Comment, American Economic Review, 87 (5), 1.033-1.039, 1997.

[30] L. Simar, P.W. Wilson. Productivity Growth in Industrialized Countries, Discussion paper $n^{\circ} 9810$, Universite Catholique de Louvain, Belgium, 1998. 
[31] P. Mitra. Innovation, inclusion and integration : from transition to convergence in Eastern Europe and the former Soviet Union, The International Bank for Reconstruction and Development / The World Bank 2008

[32] M. Nishimizu,J.M. Page. Total Factor Productivity Growth, Technological Progress and Technical Efficiency Change: Dimensions of Productivity Change in Yugoslavia, 1965-78, The Economic Journal, vol. 92, pp. 920-936, 1982.

[33] R. Solow.A Contribution to the Theory of Economic Growth. Quarterly Journal of Economics, 70:65-94, 1956.
[34] U. Varblane, P. Vahter. An analysis of the economic convergence process in the transition countries, Tartu, 2005.

[35] B. van Ark, M. O’Mahony, M.P. Timmer. The Productivity Gap between Europe and the United States: Trends and Causes, Journal of Economic Perspectives, Volume 22, Number 1, Winter 2008 - Pages 25- 44, 2008

[36] J.L. Zofio. Malmquist Productivity Index Decompositions: A Unifying Framework. Economic Analysis Working Paper Series, Universidad Autonoma de Madrid, 12, 2006. 